\title{
DESIGN OF EXPERIMENTS APPROACH TO ASSESS THE IMPACT OF API PARTICLE SIZE ON FREEZE-DRIED BULKING AGENTS
}

\author{
ȘTEFANA SUCIU ${ }^{1}$, SONIA IURIAN ${ }^{1 *}$, CĂTĂLINA BOGDAN ${ }^{2}$, LUCIA RUS $^{3}$, ALIN \\ SEBASTIAN PORAV ${ }^{4}$, GHEORGHE BORODI $^{4}$, IOAN TOMUȚÄ ${ }^{1}$ \\ ${ }^{I}$ Department of Pharmaceutical Technology and Biopharmacy, Faculty of Pharmacy, University of Medicine and Pharmacy \\ "Iuliu Hațieganu”, Cluj-Napoca, Romania \\ ${ }^{2}$ Department of Dermatology and Cosmetics, Faculty of Pharmacy, University of Medicine and Pharmacy "Iuliu \\ Hațieganu”, Cluj-Napoca, Romania \\ ${ }^{3}$ Department of Drug Analysis, Faculty of Pharmacy, University of Medicine and Pharmacy "Iuliu Hațieganu”, Cluj- \\ Napoca, Romania \\ ${ }^{4}$ National Institute for Research and Development of Isotopic and Molecular Technologies, Cluj-Napoca, Romania
}

*corresponding author: sonia.iurian@umfcluj.com

Manuscript received: June 2020

\begin{abstract}
The current work aimed at the thorough characterization of freeze-dried bulking agent structures loaded with different particle sizes of active pharmaceutical ingredient (API). Using Design of Experiments, a D-Optimal screening design was conceived in order to evaluate the influence of the formulation factors on the features of the obtained structures. The selected formulation factors were API particle size (X1), the type of the bulking agent (X2) and the ratio of the bulking agent (X3). The disintegration time, the dissolution profile and the texture characteristics were studied. The particle size of the API (ibuprofen) influenced the dissolution and the highest dissolution ratios were obtained for trehalose. The texture characteristics of the structures were influenced by the type and the ratios of bulking agents, by increasing the ratio of the bulking agent, the measured parameters were improved. Maltodextrin conducted to robust structures for which, according to the XRPD results, the particles are to a certain degree in an amorphous state. The obtained results represent a contribution to the actual knowledge in this area that can be further used in development of lyophilized pharmaceutical forms.
\end{abstract}

\section{Rezumat}

Scopul prezentei lucrări a fost caracterizarea în profunzime a structurilor obținute, prin liofilizare, în urma unui amestec format din substanță medicamentoasă și un diluant farmaceutic. Utilizând design-ul experimental a fost conceput un plan experimental de tip D-Optimal cu scopul de a evalua influența factorilor de formulare asupra caracteristicilor structurilor obținute. Factorii de formulare selectați au fost mărimea particulelor de API (X1), tipul (X2) și procentul formatorului de matriță (X3) şi s-a studiat impactul acestora asupra timpului de dezagregare, dizolvării și a caracteristicilor mecanice obținute pentru structurile liofilizate. Mărimea particulelor ingredientului activ, respectiv ibuprofen, a influențat profilul de dizolvare al acestuia, cel mai mare procent de ibuprofen dizolvat în cel mai rapid timp s-a obținut pentru formulările cu trehaloză. Caracteristicile mecanice ale structurilor liofilizate au fost influențate de tipul și procentul formatorului de matriță, cel din urmă influențând direct proporțional rezultatele. Maltodextrina a condus la obținerea unor structuri robuste, care, conform rezultatelor XRPD, demonstrează un proces de amorfizare în urma liofilizării. Rezultatele obținute reprezintă o contribuție la cunoștințele din acest domeniu care pot fi utilizate ulterior în dezvoltarea formelor farmaceutice liofilizate.

Keywords: oral lyophilisates, DoE, pharmaceutical development, ibuprofen

\section{Introduction}

In our days, the pharmaceutical industry faces a new challenge regarding the development of a suitable oral drug delivery system that allow individualized medication, accurate dosing and that overcome the well-known disadvantages of the administration route. Different dosage forms have been proposed in order to achieve a high patient compliance and therapeutic effect improvements [9].

Novel orodispersable dosage forms (ODx) gained interest not only due to the ease of administration, which makes them suitable for special populations and results in patients range extension, but also for their potential of increasing the bioavailability of active pharmaceutical ingredients (APIs) [17]. These new attractive pharmaceutical forms disintegrate in the saliva within seconds, allowing an outstanding ease of administration [3]. Some of them have already been released to the pharmaceutical market; still, various manufacturing processes and formulations available in literature were not yet implemented into the pharmaceutical production lines and are under continuous research and development [26].

Within the manufacturing methods of the ODx are direct compression, tablet molding, spray drying, 3D 
FARMACIA, 2021, Vol. 69, 2

printing and freeze-drying $[1,4,14,16,28]$. Freezedrying process has reached wider dimensions since it was applied for the preparation of oral lyophilisates (OLs). The complexity of the process and the fact that both formulation and process variables influence the final freeze-dried product's characteristics, conducted to a variety of research papers in which the principles of the Quality by Design were applied to gain knowledge and fulfil the quality attributes of the lyophilisates $[20,23,25]$. The most important drawback in the mass use of OLs is their brittle structure that requires special packaging methods and careful manipulation. Most of the oral lyophilisates contain insoluble APIs. During preparation, settlement or separation phenomena can occur that lead to critical quality attributes' (CQAs) variations. The variability could be managed by increasing the ratios of hydrophilic polymer which acts like a matrix forming agent, but has a negative effect on disintegration and dissolution or by API particle size modulation. However, API particle size could impact the disintegration time, dissolution profile and mechanical structure.

This work aimed at a better description of the interactions between the bulking agents (BA) and API, without the polymer influence. The novel aspect is the focus on how different particle sizes of API and different ratios of bulking agents affect the morphology and pharmaceutical properties of lyophilized structures.

\section{Materials and Methods}

\section{Materials}

Ibuprofen was selected as model of active substance and three grades of particle sizes were chosen: ibuprofen $25 \mu \mathrm{m}, 50 \mu \mathrm{m}$ (BASF Ludwigshafen, Germany) and $75 \mu \mathrm{m}$ (Indukern Chemie AG, Switzerland). The sorts of ibuprofen were procured directly from the manufacturer as it is; the specification of the product contains the particle size distribution within the batch. The filling agents selected for this study were mannitol (Merck, USA), trehalose dihydrate (Sigma Aldrich, USA) and maltodextrin (Glucidex, Roquette, France). The solvent was distilled water.

Design of Experiments ( $D o E$ )

The study was performed in accordance to a D-Optimal screening experimental design, with three independent variables and three variation levels, developed using Modde 12 software (Sartorius Stedim, Sweden). According to the DoE, 18 runs and 3 replicated centre points were generated, as shown in Table I.

The quantitative independent selected variables were represented by the particle size of ibuprofen (X1) (25 $\mu \mathrm{m}, 50 \mu \mathrm{m}$ and $75 \mu \mathrm{m})$ and by the percentage of bulking agent (X3) $(2.5 \%, 5 \%$ and $7.5 \%)$. The qualitative input was the type of bulking agent (X2) (mannitol, trehalose and maltodextrin).
Table I

Experimental design matrix

\begin{tabular}{lcccc}
\hline Exp Name & Run Order & X1 & X2 & X3 \\
\hline N1 & 1 & 25 & mannitol & 2.5 \\
N2 & 7 & 75 & mannitol & 2.5 \\
N3 & 18 & 25 & mannitol & 7.5 \\
N4 & 17 & 75 & mannitol & 7.5 \\
N5 & 16 & 50 & mannitol & 5 \\
N6 & 12 & 25 & trehalose & 2.5 \\
N7 & 20 & 75 & trehalose & 2.5 \\
N8 & 4 & 25 & trehalose & 7.5 \\
N9 & 9 & 75 & trehalose & 7.5 \\
N10 & 3 & 50 & trehalose & 5 \\
N11 & 11 & 25 & maltodextrin & 2.5 \\
N12 & 5 & 75 & maltodextrin & 2.5 \\
N13 & 2 & 25 & maltodextrin & 7.5 \\
N14 & 14 & 75 & maltodextrin & 7.5 \\
N15 & 10 & 25 & maltodextrin & 5 \\
N16 & 19 & 75 & maltodextrin & 5 \\
N17 & 8 & 50 & maltodextrin & 2.5 \\
N18 & 6 & 50 & maltodextrin & 7.5 \\
N19 & 13 & 50 & mannitol & 5 \\
N20 & 15 & 50 & mannitol & 5 \\
N21 & 21 & 50 & mannitol & 5 \\
X1 - API particle size $(\mu \mathrm{m}) ;$ X2 - bulking agent type; X3 -
\end{tabular}

percentage of the bulking agent

The responses were selected from the classical characterization methods applied for oral lyophilisates. These include features that are linked to the safety, efficacy and quality of a pharmaceutical product and are the following: aspect, disintegration time, dissolution profile and mechanical properties. As general requirements for freeze-dried products, the aim is to obtain weight uniformity between units, robust structures without collapse signs that disintegrate rapidly, in less than 3 minutes and high dissolution rates of the API, more than $90 \%$ in 30 minutes. The integrity of the structures during handling and storage has to be ensured, as well.

The same software, Modde 12 (Sartorius Stedim, Sweden) was used for data processing, fitting and statistical parameters calculation. To evaluate the influences of the independent variables on the responses partial least squares (PLS) method was used and the statistical parameters considered were: $\mathrm{R}^{2}$ as the variation explained by the model and $\mathrm{Q}^{2}$ as the fraction of the variation of the response that can be predicted by the model. Anova test (variance analysis) was applied for all the responses in order to evaluate the validity of the experimental design.

\section{Preparation of lyophilisates}

According to the aforementioned experimental design matrix, a total number of 21 formulations were prepared by dissolving the indicated amount of the bulking agent into distilled water. The ibuprofen was suspended in the obtained solution. The suspensions prepared to a content of $50 \mathrm{mg} / \mathrm{mL}$ ibuprofen, were transferred in blister pockets with volume of $1 \mathrm{~mL}$ each. The filled blisters pockets were lyophilized using freeze-drying 
FARMACIA, 2021, Vol. 69, 2

equipment VirTis Advantage Plus (SP Scientific, USA). The freeze-drying equipment shelf was cooled at $-55^{\circ} \mathrm{C}$, the suspensions were exposed directly to this temperature in order to avoid sedimentation or dissolution before freezing. This way the variability induced by dissolution was diminished. The samples were kept under this temperature, at 350 Torr pressure, for 20 hours. The primary drying step was performed at $25^{\circ} \mathrm{C}$ for 40 hours and a pressure of $180 \mathrm{mTorr}$. The secondary drying step was performed at $10^{\circ} \mathrm{C}$ under a pressure of 300 mTorr, for 10 hours. Following the preparation, lyophilisates were stored in the desiccator at room temperature until the analysis execution.

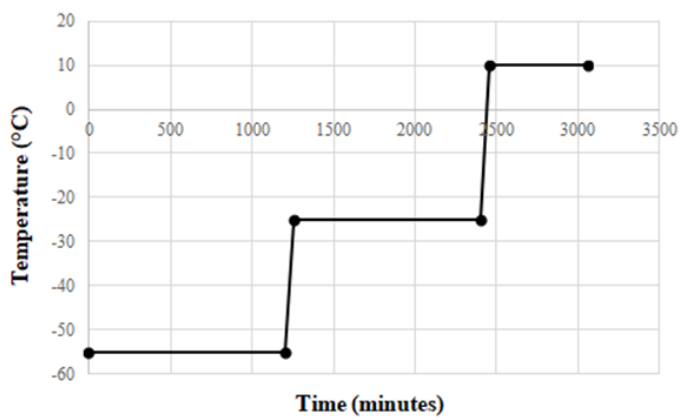

Figure 1.

Freeze-drying cycle (temperature $v s$. time profile)

Pharmaceutical characterization of lyophilisates

The disintegration time was measured on six lyophilisates from each formulation, in compliance with the European Pharmacopeia method [13]; each lyophilisate was placed in $200 \mathrm{~mL}$ distilled water, kept at $37^{\circ} \mathrm{C}$ and the time needed for complete disintegration was recorded using a digital stopwatch. The mean disintegration time and standard deviation were calculated for each formulation and the disintegration time values were analysed as response Y1 in the DoE.

The in vitro dissolution tests were performed according to the method described in the European Pharmacopoeia [13]. The dissolution tester equipped with rotating paddles (Pharma Test PT-DT 7, Germany) was used and the method consisted in dissolving the lyophilisate in $900 \mathrm{~mL}$ dissolution media, respectively phosphate buffer $\mathrm{pH} 7.2 \mathrm{kept}$ at $37^{\circ} \mathrm{C}$ and $50 \mathrm{rpm}$ rotation speed. $5 \mathrm{~mL}$ aliquots were sampled at 5, 10, 15, 20 and 30 minutes and the dissolved API was quantified by a UV spectrophotometric method (Analytik Jena, Germany) at a wavelength of $221 \mathrm{~nm}$. The mean dissolved ibuprofen ratios and standard deviation were calculated out of three measurements. The ratios of dissolved ibuprofen after 5 minutes (Y2) and 10 minutes (Y3) were included as responses into the DoE.

Texture Analysis. The assessment of the mechanical properties of the lyophilisates was done with a CT3 texture analyser (Brookfield Engineering, USA). The method entailed a compression test applied on each lyophilisate. A cylindrical probe applying a load of $50 \mathrm{~g}$ constantly pressed the freeze-dried product with a speed of $0.1 \mathrm{~mm} / \mathrm{s}$, down to a depth of $1 \mathrm{~mm}$. The behaviour of the structures was evaluated based on load vs. distance graphical curves and characterization was defined based on the resistance of the material to the applied pressure. For each formulation, six lyophilisates were used and the average and standard deviation were considered for the following parameters: hardness (Y4), rigidity (Y5), fracturability (Y6), resilience (Y7) and load of target (Y8).

Differential Scanning Calorimetry (DSC). The crystallization process following the freeze-drying cycle was study using DSC 822 (Mettler Toledo, USA). The temperature interval for the analysis was selected in the range $25-400^{\circ} \mathrm{C}$, the increase of temperature was set to be with $10^{\circ}$ per minute rate. Measurements were performed under dynamic $\mathrm{N}_{2}$ atmosphere with a $50 \mathrm{~mL} / \mathrm{min}$ flow rate. Approximatively $2.5 \mathrm{mg}$ of each sample was weighted and transferred in $100 \mu \mathrm{L}$ aluminium crucibles, hermetically sealed and pierced. Analysis was done in parallel with an empty hermetically sealed and pierced $100 \mu \mathrm{L}$ aluminium crucible as a reference. The thermograms were obtained and interpreted using software $\operatorname{Star}^{\mathrm{e}} \mathrm{SW}$ v.12.10.

$X$-Ray Powder Diffraction (XRPD). The XRPD method was applied for lyophilisates characterization. The XRPD data was obtained using a Bruker D8 Advance diffractometer in the Bragg-Brentano geometry. The diffractometer is equipped with a Ge (111) monochromator in the incident beam in order to remove $\mathrm{CuK} \beta$ and $\mathrm{CuK} \alpha 2$ radiation in order to obtain a monochromatic beam corresponding to $\mathrm{CuK} \alpha 1$ radiation with wavelength of $1.54056 \AA$. The XRPD patterns were recorded with a super speed LynxEye position detector.

Scanning Electron Microscopy (SEM). In order to sustain and complete the DSC and XRPD results, as well as to assess the morphology of lyophilisates structures, they were examined by SEM. The samples were placed on a $2 \mathrm{~cm}$ Leit tab over an aluminium $\mathrm{stub}$, followed by a $10 \mathrm{~nm}$ gold coating in order to reduce the charging of the samples. Coating was done with a Quorum Sputter Coater Q150T ES. SEM analysis was done at $10 \mathrm{kV}$ using a Hitachi SU8230 High Resolution microscope equipped with a cold field emission gun.

\section{Results and Discussion}

Since most of the APIs are insoluble in water, settlement or separation can occur during preparation and might lead to high variability of the lyophilized structures. In this respect, the objective of the study was to evaluate the influence of the formulation factors on the features and behaviour of the lyophilized structures. It was aimed for a better description of the interactions between the bulking agent and API, without the influences of the matrix forming polymers; moreover, the study meant a deep investigation on how different 
FARMACIA, 2021, Vol. 69, 2

particle sizes of API affect the morphology and pharmaceutical properties of lyophilized structures. The study was conceived based on the results of preliminary experiments and observations from previous studies and entailed two quantitative inputs and one

qualitative: the type of API particle size (X1), the type (X2) and the percentage of the bulking agent (X3). For the DoE analysis, the results presented in the table below (Table II) were considered. Each formulation was tested and the results were listed for all the responses.

Table II

Results matrix

\begin{tabular}{|c|c|c|c|c|c|c|c|c|}
\hline $\begin{array}{l}\text { Exp } \\
\text { Name }\end{array}$ & $\begin{array}{c}\text { Disintegration } \\
\text { time (s) } \\
\text { Y1 }\end{array}$ & $\begin{array}{c}\text { Dissolution } \\
\text { at } 5 \text { min }(\%) \\
\text { Y2 }\end{array}$ & $\begin{array}{c}\text { Dissolution at } \\
10 \text { min }(\%) \\
\text { Y3 }\end{array}$ & $\begin{array}{c}\text { Hardness } \\
\text { (g) } \\
\text { Y4 } \\
\end{array}$ & $\begin{array}{c}\text { Rigidity } \\
\text { (g) } \\
\text { Y5 }\end{array}$ & $\begin{array}{c}\text { Fracturability } \\
\text { (g) } \\
\text { Y6 } \\
\end{array}$ & $\begin{array}{c}\text { Resilience } \\
\text { Y7 }\end{array}$ & $\begin{array}{c}\text { Load at } \\
\text { target }(\mathrm{g}) \\
\text { Y8 }\end{array}$ \\
\hline N1 & 1.88 & 97.5 & 100.0 & 35.10 & 21.70 & 5.30 & 0.03 & 34.50 \\
\hline $\mathrm{N} 2$ & 0.61 & 93.0 & 98.8 & 42.20 & 25.20 & 5.20 & 0.03 & 41.90 \\
\hline N3 & 1.45 & 93.3 & 99.6 & 168.80 & 110.60 & 66.20 & 0.02 & 167.40 \\
\hline N4 & 1.82 & 85.7 & 95.9 & 157.20 & 82.80 & 30.80 & 0.01 & 154.00 \\
\hline N5 & 0.69 & 93.9 & 99.9 & 107.90 & 66.70 & 19.90 & 0.01 & 98.20 \\
\hline N6 & 0.71 & 98.9 & 98.8 & 34.90 & 16.50 & 7.80 & 0.02 & 34.80 \\
\hline N7 & 1.20 & 92.5 & 97.6 & 39.10 & 31.80 & 7.80 & 0.03 & 38.30 \\
\hline N8 & 1.41 & 100.2 & 99.9 & 88.00 & 30.00 & 8.00 & 0.04 & 85.90 \\
\hline N9 & 0.52 & 85.2 & 98.9 & 114.00 & 35.50 & 23.70 & 0.01 & 113.90 \\
\hline N10 & 1.15 & 99.0 & 99.4 & 61.80 & 20.10 & 6.70 & 0.02 & 61.80 \\
\hline N11 & 1.73 & 98.8 & 99.6 & 90.80 & 43.40 & 42.50 & 0.11 & 90.40 \\
\hline N12 & 2.65 & 97.9 & 99.4 & 220.60 & 75.30 & 220.60 & 0.16 & 220.60 \\
\hline N13 & 1.11 & 97.4 & 100.0 & 548.50 & 103.40 & 548.50 & 0.24 & 548.50 \\
\hline N14 & 1.16 & 89.6 & 94.8 & 607.40 & 250.60 & 579.10 & 0.11 & 607.40 \\
\hline N15 & 1.29 & 99.4 & 99.8 & 335.70 & 128.30 & 335.70 & 0.13 & 335.70 \\
\hline N16 & 1.10 & 89.5 & 97.7 & 352.70 & 126.80 & 283.70 & 0.16 & 352.70 \\
\hline N17 & 2.93 & 99.1 & 100.0 & 129.80 & 51.80 & 111.40 & 0.17 & 129.80 \\
\hline N18 & 1.67 & 99.5 & 100.0 & 809.10 & 268.80 & 809.10 & 0.18 & 805.80 \\
\hline N19 & 0.58 & 95.0 & 99.9 & 86.00 & 48.20 & 28.80 & 0.02 & 81.90 \\
\hline N20 & 0.44 & 93.6 & 100.0 & 102.60 & 60.90 & 23.80 & 0.01 & 94.80 \\
\hline N21 & 1.06 & 91.9 & 98.1 & 89.80 & 47.80 & 14.50 & 0.02 & 89.00 \\
\hline
\end{tabular}

The statistical analysis revealed significant models for all the responses. The revised values of the regression coefficients of the model equations were listed in Table III. The $\mathrm{R}^{2}$ coefficient was above 0.9 for responses Y4, Y6, Y7 and Y8. For responses Y1, Y2, Y3 and Y5 the coefficient was between 0.63 and 0.85 . These results show a good fit of the experimental data to the developed models. Anova test was applied and for all the responses the significance $p$-value was below 0.05 and $p$-error was above 0.05 . The magnitude of the effects of formulation variables on the responses is represented by the coefficient values and their sign indicates a positive or a negative influence on the response.

Table III

Summary of fit

\begin{tabular}{cccccccc}
\hline Response & $\mathbf{R}^{\mathbf{2}}$ & $\mathbf{Q}^{\mathbf{2}}$ & $\boldsymbol{p}$-value & $\boldsymbol{p}$-error & F-value & Model validity & Reproducibility \\
\hline Y1 & 0.63 & 0.24 & 0.017 & 0.144 & 3.92 & 0.52 & 0.84 \\
Y2 & 0.85 & 0.64 & $<0.001$ & 0.192 & 13.15 & 0.59 & 0.92 \\
Y3 & 0.78 & 0.30 & 0.007 & 0.175 & 5.40 & 0.56 & 0.91 \\
Y4 & 0.94 & 0.79 & $<0.001$ & 0.112 & 31.44 & 0.45 & 0.98 \\
Y5 & 0.83 & 0.57 & $<0.001$ & 0.228 & 10.97 & 0.63 & 0.89 \\
Y6 & 0.95 & 0.72 & $<0.001$ & 0.078 & 29.69 & 0.36 & 0.98 \\
Y7 & 0.90 & 0.66 & $<0.001$ & 0.229 & 27.87 & 0.63 & 0.94 \\
Y8 & 0.94 & 0.83 & $<0.001$ & 0.188 & 36.57 & 0.58 & 0.97
\end{tabular}

$\mathrm{R}^{2}$ - fraction of the variation of the response explained by the model; $\mathrm{Q}^{2}$ - predictive power of the model, $\mathrm{p}$-values; $\mathrm{p}$-error; F-value - the ratio of the mean regression; Model validity - the extent to which the measurement corresponds to the real world; Reproducibility - ability to produce the same output if the input is the same; Y1 - mean disintegration time, $\mathrm{Y} 2$ - \% of dissolved ibuprofen at $5 \mathrm{~min} ; \mathrm{Y} 3$ - \% of dissolved ibuprofen at $10 \mathrm{~min}$; Y4 - hardness; Y5 - rigidity; Y6 - fracturability; Y7 - resilience; Y8 - load at target.

\section{Appearance evaluation}

The appearance was evaluated in order to identify any physical defects, the lack of uniformity between different units, signs of structure collapse.

Following the lyophilization, all formulations exhibited an elegant macroscopic appearance without defects.
The most fragile were the formulations with mannitol, the handling and taking out from the blister pockets was difficult. Trehalose use conducted to porous structures, fragile as well during manipulation, but manageable with care. For maltodextrin, it was observed that all the obtained structures were robust and resistant 
to handling and manipulation. No signs of structure collapse were identified and during storage in the desiccator, no significant changes of the texture were observed.

In vitro disintegration time (Y1)

The measured disintegration times varied between 0.4 seconds and 2.9 seconds; all the formulations were rapidly disintegrated and the difference between the disintegration times measures were not highly significant. The model coefficients revealed that the API particle size does not influence this parameter, but a nonlinear effect was observed for the bulking agent ratio (X3). The highly robust structures with maltodextrin conducted to a longer disintegration time when compared with the other two excipients. The fragile and porous structures obtained for mannitol and trehalose had short disintegration times down to a minimum of $0.4 \mathrm{~s}$. The fast disintegration times can be explained by the ability of the excipients to facilitate the water absorption in the structures [1]. In case of future studies, the ratios of bulking agents should be carefully set since it was observed that above a certain percentage, the increase of BA is increasing the disintegration time. This behaviour might be explained by the structure density increase, clearly observed during the aspect evaluation.

The samples surface plots (Figures 2a, 2b and 2c) revealed that the disintegration time decreases when the bulking agent ratio increases from $2.5 \%$ up to $5 \%$. Higher BA ratios lead to disintegration time increase. This behaviour is similar for all three bulking agents used regardless of their solubility, which indicates the porosity and physical appearance as a possible cause.
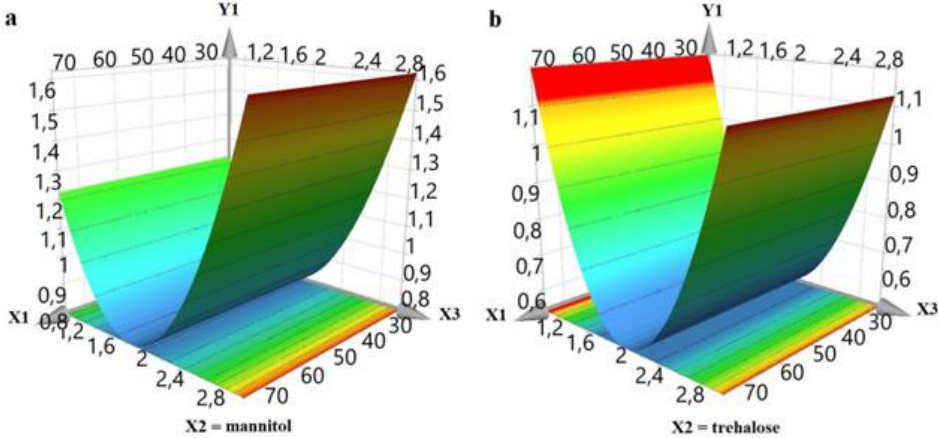

Figure 2.

Influence of the formulation factors on the disintegration time (Y1)

(a) mannitol samples surface plot; (b) trehalose samples surface plot (c) maltodextrin samples surface plot; X1 - API particle size; X2 - bulking agent type; X3 - percentage of the bulking agent

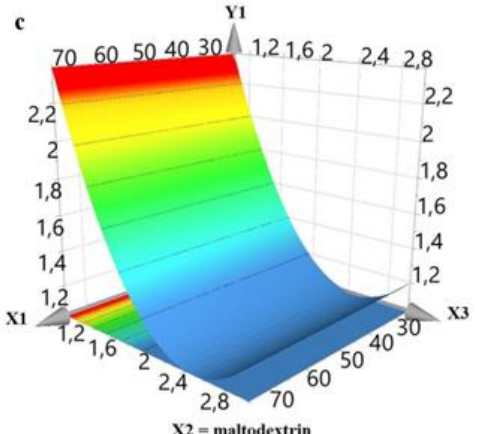

= maltodextrin

formulations were completely dissolved with no more relevant differences or influences of input factors.

Many research papers have focused on the link between particle size and final product attributes regarding dissolution rate, absorption rate, or bioavailability of the API. The decrease of the drug particle size entails the increase of the specific surface area that leads to higher dissolution rates [8]. parameter were found only for the first two sampling times (after 5 and 10 minutes). After 15 minutes, all the
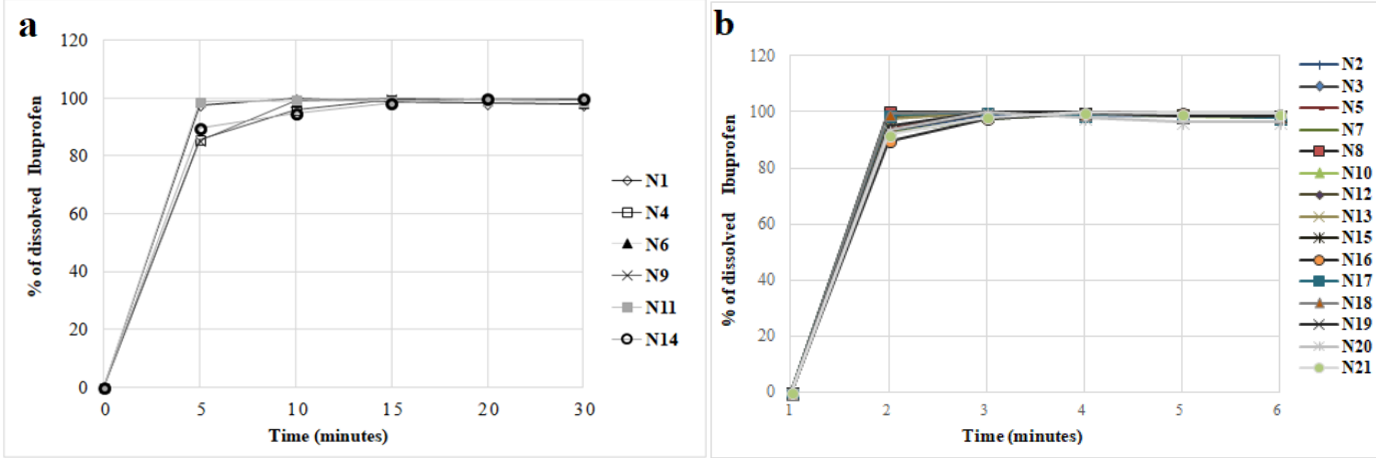

Figure 3.

Dissolution profiles of selected formulations N1, N4, N6, N9, N11 and N14 (a), as \% of dissolved ibuprofen $v s$. time; supplementary plot for dissolution profiles (b) 
As shown in the coefficient plots (Figures $4 \mathrm{a}$ and $4 \mathrm{~b}$ ), the released API ratio was influenced by the API particle size; the increase of the API particle size (X1) led to slower ibuprofen dissolution. The same effect was obtained for the bulking agent ratio (X3): high ratios of BA determined lower values of dissolved API ratios. For both dissolution related responses (Y2 and Y3), the quantitative factors' effects were significant $(\mathrm{p}<0.05)$. Regarding the type of bulking agent, is also had an impact on dissolution, with a positive effect from trehalose and maltodextrin and a negative effect from mannitol. Trehalose and maltodextrin are more soluble in water (1:1.45 g) when compared to mannitol (1:5.5 g) which allowed faster water absorption into the freeze-dried matrix and faster disintegration prior to dissolution [21]. The disintegration of the structures precedes the dissolution, step that influences only the 5 minutes dissolution results. This means that the BA type is influencing the features and behaviour of the structures; for example, low density and fragile structures disintegrate faster and the dissolution is higher than for the increased density and compact structures that have a prolonged disintegration and a low dissolution percentage after 5 minutes. For this study, the dissolution results were appropriate, even though it was observed that the BA type influence becomes levelled for responses obtained at 10 minutes dissolution. As previously shown, it was also observed that the moistening of the sample, respectively the disintegration is enhanced if the bulking agent ratio is decreased and based on the influences observed and on the results obtained, it can be stated that the optimum API particles size for a very good dissolution is between 25 and $50 \mu \mathrm{m}$ (Figure 4 - surface plots). This is a slight influence, since between the results for dissolution a low variability was observed. The minimum result obtained after 5 minutes was $75.9 \%$, while after 10 minutes the lowest dissolution was $78.3 \%$, demonstrating a very good dissolution performance of the API from the freeze-dried products.
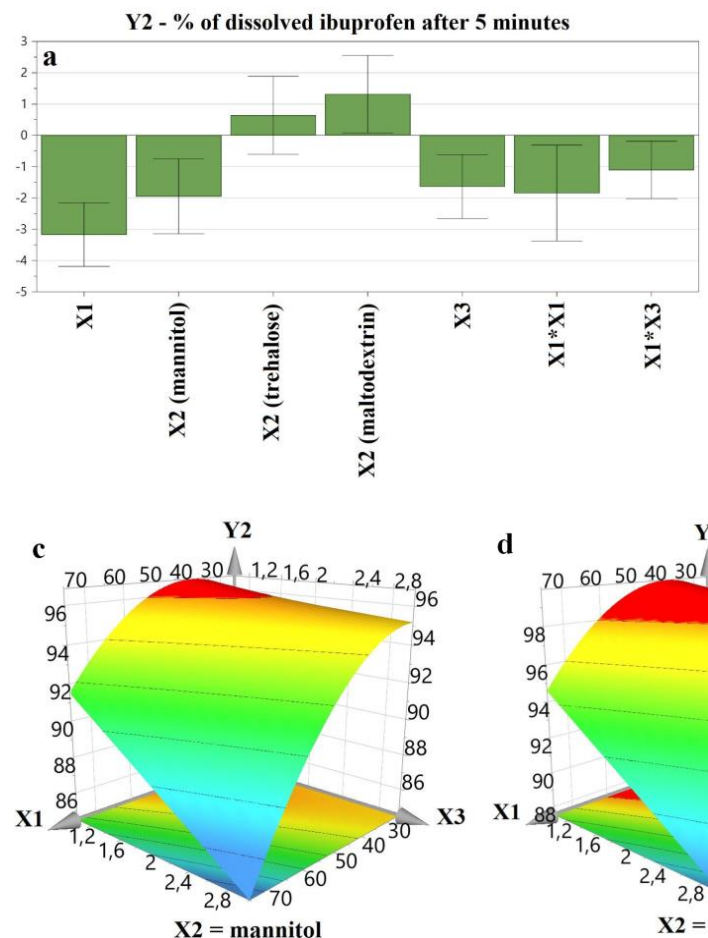

Y3

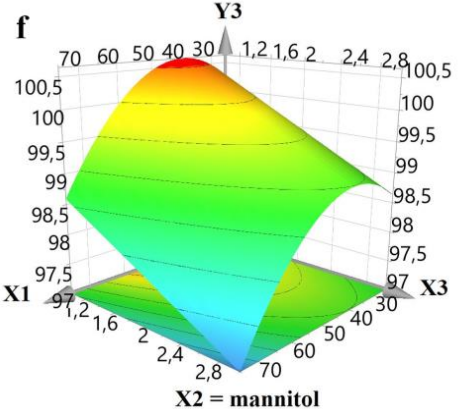

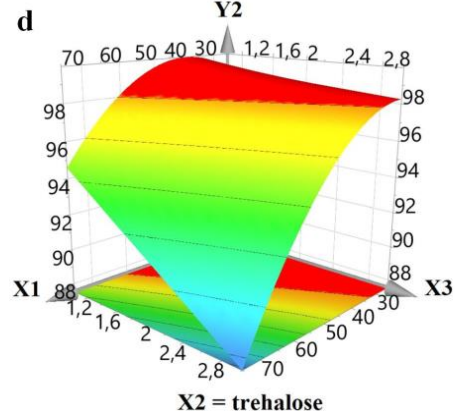

Y3

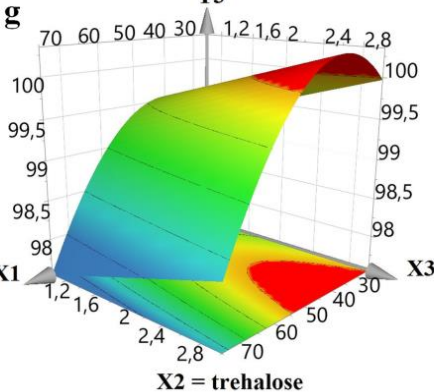

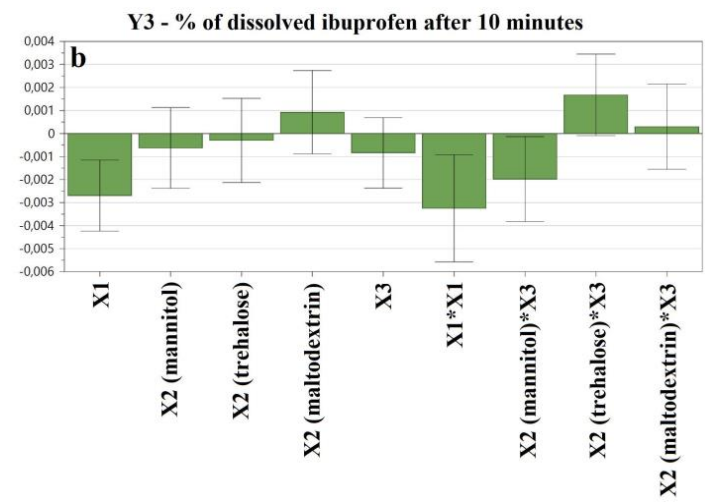

Y2

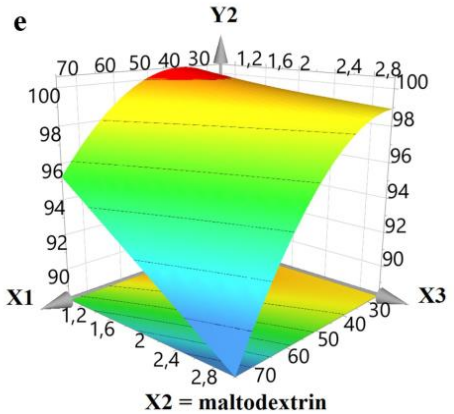

Y3

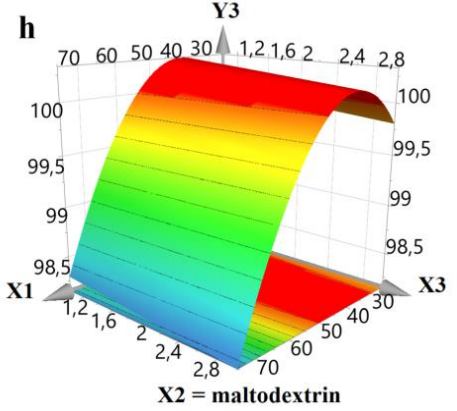

Figure 4.

The influence of formulation factors on the \% of dissolved ibuprofen after 5 minutes (Y2) and 10 minutes (Y3) shown as coefficient plots $(\mathrm{a}, \mathrm{b})$ and response surfaces $(\mathrm{c}, \mathrm{d}, \mathrm{e}, \mathrm{f}, \mathrm{g}, \mathrm{h})$

X1 - API particle size; X2 - bulking agent type; X3 - percentage of the bulking agent 
FARMACIA, 2021, Vol. 69, 2

Texture analysis ( $Y 4$ - Y8)

In the area of lyophilisates, mechanical properties are regarded as critical quality attributes (CQAs) of the final product. An adequate handling and administration of these highly porous and fragile structures impose an appropriate mechanical resistance. Following the latest trend of the industry and applying a risk analysis (Isikawa diagram - FMEA analysis), Casian et al. set within the target profile of the lyophilsate a mechanical resistance above $300 \mathrm{~g}$ of load. The results of the optimisation revealed the need to design a structure with high mechanical resistance, above $600 \mathrm{~g}$ [7].

For this study, the mechanical properties and the behaviour of all the structures obtained was evaluated through texture analysis resulting in a texture profile. Figure 5a is the graphical representation of the structures' behaviour expressed as load vs. time curves; the representation was done for six selected formulations (N1, N4, N6, N9, N11 and N14) which represent the extreme limits of variation for each filler from the DoE (low and high BA\%, small and large particle size API). This way, the graphic underlines the behaviour variations and allows an overview of the results. This analysis led to the calculation of the hardness (Y4), rigidity (Y5), fracturability (Y6), resilience (Y7) and load at target (Y8) which were further analysed as responses in the DoE.

The hardness can be translated in the total resistance of the structure obtained when pressure is applied with a cylindrical probe and maximum load is reached [6]. The coefficient plot was generated for the hardness (Figure 5b) and showed that it was influenced by the type (X2) and the ratio of the BA (X3). The raw results conducted to the following conclusions: for the formulation with mannitol the minimum value was $35.1 \mathrm{~g}$ obtained for $\mathrm{N} 1$ (ibuprofen $25 \mu \mathrm{m}, 2.5 \%$ mannitol); the hardness is increased with the increase of the BA ratio (X3), the maximum value for this excipient was $168.8 \mathrm{~g}$ recorded for N3 (ibuprofen 25 $\mu \mathrm{m}, 7.5 \%$ mannitol). Low hardness values for different lyophilized formulations with mannitol were previously obtained and reported in the literature [27]. The minimum result obtained for the structures with trehalose was $34.9 \mathrm{~g}$ recorded for N6 (ibuprofen $25 \mu \mathrm{m}, 2.5 \%$ trehalose) and the maximum $114.0 \mathrm{~g}$ for N9 (ibuprofen $75 \mu \mathrm{m}$, $7.5 \%$ trehalose). The use of maltodextrin conducted to structures with higher hardness, the minimum obtained was $90.8 \mathrm{~g}$ for N11 (ibuprofen $25 \mu \mathrm{m}, 2.5 \%$ maltodextrin) and the maximum was $809.1 \mathrm{~g}$ for N18 (iburofen 75 $\mu \mathrm{m}, 7.5 \%$ maltodextrin).

The rigidity was determined by applying pressure with the cylindrical probe down to a depth of $1 \mathrm{~mm}$ into the sample structure. High amounts of maltodextrin
(5\% and $7.5 \%)$ conducted to the highest results with a maximum value of $268.8 \mathrm{~g}$. The lowest rigidity of $16.5 \mathrm{~g}$ was recorded for the formulation containing ibuprofen $25 \mu \mathrm{m}$ and $2.5 \%$ trehalose. Figure $5 \mathrm{c}$ reveals that the type (X2) and ratio of BA (X3) had an influence on this parameter. The increase of the BA ratio conducts to higher rigidity for maltodextrin formulations and lower rigidity for trehalose and mannitol formulations.

The fracturability can be considered as an indirect indicator for the friability of the structures as it shows the load applied that determines the structure breakage. The fracture itself is represented by the breaking of the structure walls under the applied load. The influences observed on the fracturability are represented in Figure $5 \mathrm{~d}$ and are very similar to those obtained for hardness, with a maximum of $809.1 \mathrm{~g}$ recorded for formulation N18 (ibuprofen $50 \mu \mathrm{m}$ and $7.5 \%$ maltodextrin) and a minimum of $5.2 \mathrm{~g}$ for the formulation $\mathrm{N} 2$ (ibuprofen 75 $\mu \mathrm{m}$ and $2.5 \%$ mannitol). The aforementioned parameters were influenced by the thickness, elasticity, nature and number of the pores formed in the mesh. As shown in the coefficient plot (Figure 5d), none of the aforementioned parameters were influenced by the API particle size (X1), and the pattern of the influence is similar for all three responses Y4, Y5 and Y6 (as presented in Figures $5 \mathrm{~b}, 5 \mathrm{c}$ and $5 \mathrm{~d}$ ). The mechanical properties were influenced only by the type (X2) and the ratio of the BA (X3). The use and increase of ratio for the maltodextrin led to robust structures, with increased mechanical properties. On the contrary, the use and increase of trehalose and mannitol ratios conducted to structures with low hardness.

The resilience (Y7) is the parameter used to measure the way the material recovers from deformation in relation with the speed of the probe and the applied loads [27]. In addition to the influences described for the first three texture parameters (Y4 - Y6), the resilience was influenced negatively by simultaneous increase of the API particle size (X1) and bulking agent ratio (X3), as shown in the coefficient plot (Figure 5e). Apparently, high API particle sizes loaded on dense BA structures determine the stiffening of the structures and a fracturing tendency when submitted to pressure.

The load at target (Y8) is related to the resistance of the product when the designated target load is reached [6]. The influence patterns were similar as those obtained for the hardness (Y4) (Figure 5f). This response was influenced by the type (X2) and the ratio of the bulking agent (X3), maltodextrin use had a positive influence, while mannitol and trehalose had a negative influence (Figure 5f). 

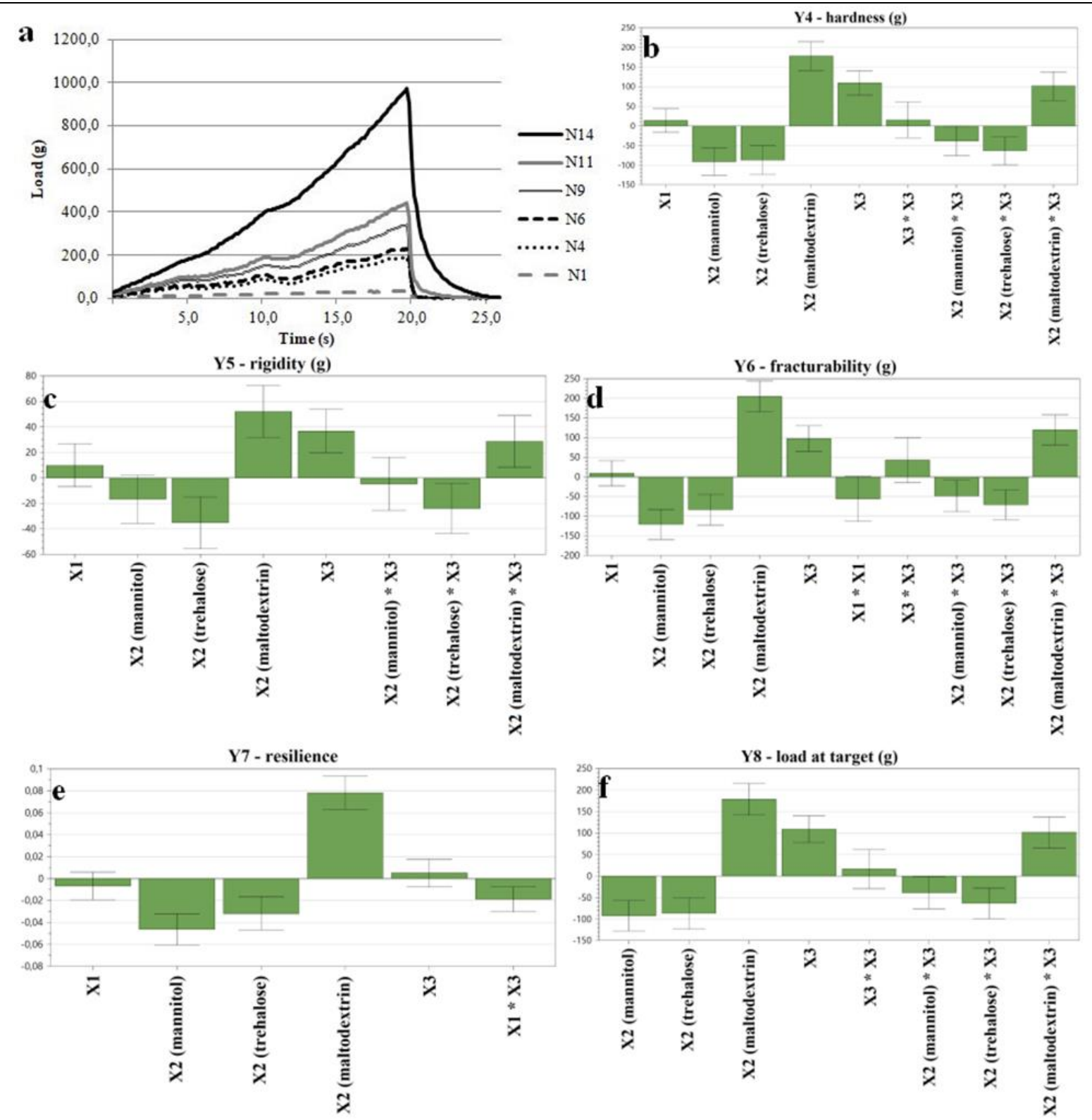

Figure 5.

Texture analysis results

(a) texture profile for formulations N1, N4, N6, N9, N11 and N14; coefficient plots showing formulation factors effects on (b) hardness (Y4); (c) rigidity (Y5); (d) fracturability (Y6); (e) resilience (Y7); (f) load at target (Y8)

\section{Solid state analysis}

In order to perform a qualitative and/or a quantitative evaluation of the crystalline state in the sample or to determine whether amorphization or crystallization processes occur during different treatments like processing, storage or thermal treatments as heating or melting, DSC coupled with XRPD technique can be used. Even though XRPD is more frequently used for this purpose, several papers report results in which both techniques are applied to provide a deeper understanding regarding the crystallinity of the analysed samples [5, 24].

A qualitative evaluation was pursued in this study, the solid state of the unprocessed ibuprofen was evaluated through both of the selected techniques (as depicted in Figure 6). The thermograms and diffractograms obtained for the pure API were used as a comparison with the freeze-dried samples` analysis.

The DSC analysis revealed for all the formulations, an endothermic peak in the range of $76-78^{\circ} \mathrm{C}\left( \pm 2{ }^{\circ} \mathrm{C}\right)$; this confirms the existing literature data which reports a melting point at $77.5^{\circ} \mathrm{C}$ for ibuprofen in a crystalline state [2]. The specific thermal behaviour the BAs was also identified, a melting point of $165^{\circ} \mathrm{C}$ for mannitol, for trehalose an endothermic peak was present in the range of $94-96^{\circ} \mathrm{C}$, while maltodextrin showed degradation signs around $240^{\circ} \mathrm{C}$ (Figures $6 \mathrm{a}$ and $6 \mathrm{~b}$ ). The thermal analysis revealed signs of amorphization of the API in some of the thermograms, displayed as smaller and broadened peaks when compared with 
the individual API. The characterization was done based on the area of ibuprofen melting peak $(\mathrm{J} / \mathrm{g})$, the other thermal events observed were out of the scope in this case [22]. The area of the melting peak obtained for the pure API was $126.44 \mathrm{~J} / \mathrm{g}$ and the sharpness of the peak indicated a high crystalline ratio. The degree of crystallinity varied within the formulation set. The DSC curves of the samples revealed smaller and broader peaks. This suggested that the formulations contained mixtures of crystalline and amorphous ibuprofen that coexisted. The area of melting peaks obtained for the samples varied between $12.73 \mathrm{~J} / \mathrm{g}$ and $115.28 \mathrm{~J} / \mathrm{g}$.

XRPD diffractograms (Figures 6c and 6d) completed the DSC results and revealed differences between the samples. The formulations with maltodextrin conducted to diffractograms which indicated strong intermolecular interactions between the API and excipient. Based on the diffractograms obtained for unprocessed ibuprofen and maltodextrin samples (N11 with $2.5 \%$ and N14 with $7.5 \%$ maltodextrin), represented in Figure 6d, it can be stated that the increase of the BA ratio conducts to a more visible amorphization process. The amorphous state generates a higher solubility of the ibuprofen, confirmed by the dissolution profiles obtained for formulations N11 and N14 and by similar research papers $[2,19]$.

An interaction between maltodextrin and ibuprofen was described by Garnero et al., based on the XRPD and SEM analyses, confirming that the solubility of ibuprofen was improved by the addition of maltodextrins that led to amorphous state complexes [15]. Also, the results obtained by Garnero et al. complete the results obtained previously in various research papers that showed the benefit of the amorphization effect which occurs during the lyophilization process, on the dissolution of the APIs [10,11,18].

Dixit and his team showed that the dissolution of freeze-dried crystals is improved comparing with pure ibuprofen crystals and that during the lyophilization process the API suffered crystallinity decrease. His research team also performed stability studies for the freeze-dried samples, for a period of 90 days kept at $40^{\circ} \mathrm{C}$ and $75 \%$ relative humidity. The obtained results showed that the amorphous state of freeze-dried ibuprofen is a stable form in the conditions mentioned above [12].

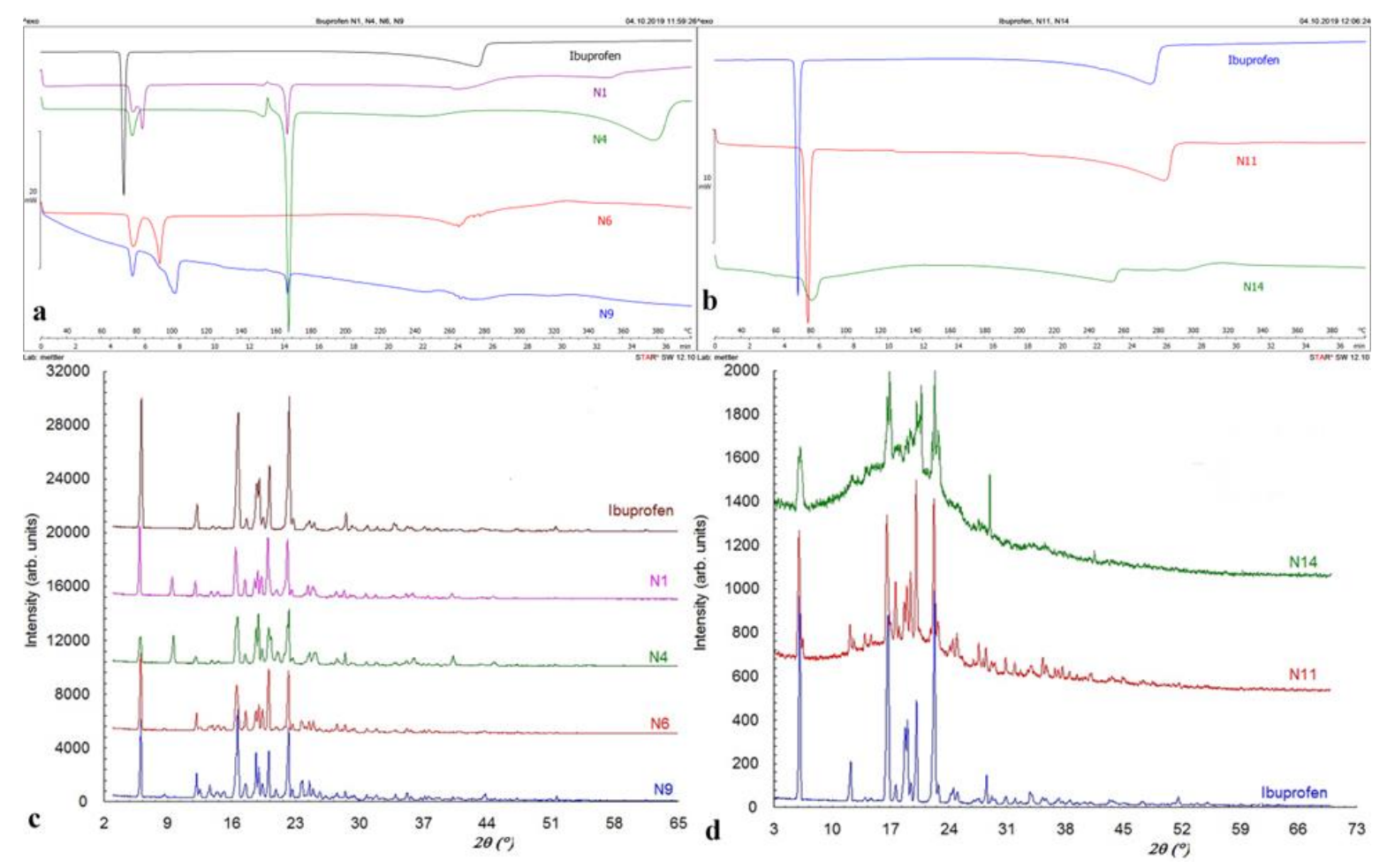

Figure 6.

DSC thermograms of mannitol and trehalose samples (a), maltodextrin samples (b); XRPD Diffractograms for mannitol and trehalose samples (c), maltodextrin samples (d)

The freeze-dried structures' morphology was investigated via SEM (Figure 7). SEM images were useful in explaining the previously obtained results, as they allowed the characterization of the lyophilized structures depending on the type of BA (X2). Figure 7a shows that the use of mannitol conducted to structures with big pores, a fragile network with large spaces, which justify rapid disintegration, high solubility, weak mechanical profiles and handling difficulties.

According to the Figure $7 b$, trehalose conducted to a more organized lamellar structure with compact walls and wide pores between layers, however not dense enough to ensure adequate texture profile and handling. 
The fragility of the structures can be explained by the stratified lamellar walls`disposition.

The images obtained for the formulations with maltodextrin (Figure 7c) were in good agreement with the texture profile and behaviour of the lyophilized structures. A highly dense network was observed, with compact walls and fringed borders, which explains a large contact surface with the disintegration media. The higher density led to prolonged disintegration time comparing with mannitol and trehalose structures, however within 3 seconds, with very good dissolution results and ease of manipulation.

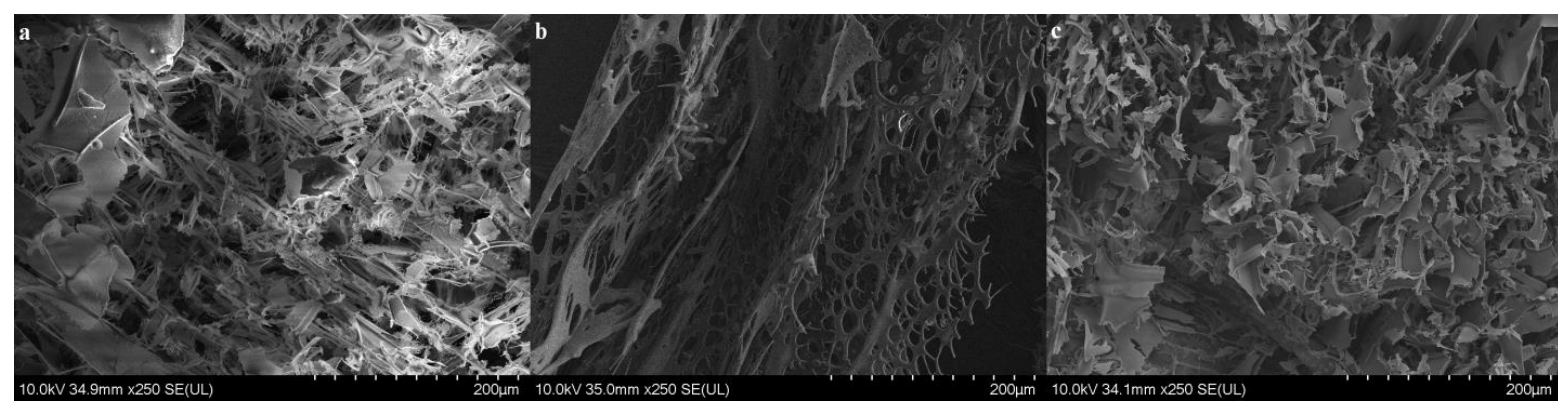

Figure 7.

SEM image for (a) mannitol formulation, (b) trehalose formulation, (c) maltodextrin formulation

\section{Conclusions}

The present work was conceived as a screening study, to assess the behaviour and interactions between freezedried bulking agents and an insoluble API with various particle sizes. In order to evaluate the influence of the API particle size on the characteristics of BA lyophilized structures, the selected model drug was ibuprofen. DoE was exploited and twenty-one experimental formulations were prepared, lyophilized and characterized. The influence of the API particle size on the dissolution was shown. Moreover, results indicated that the texture features of the lyophilisates were significantly influenced by the type and the ratio of the BA with a very slight to no influence of the API particle size.

It has been revealed that maltodextrin is a good candidate as BA, conducting to structures with good disintegration and dissolution properties, as well as a strong porous structure.

The present work represents a useful study with applicability in the area of new formulations development with ibuprofen or ibuprofen-Maltodextrin freeze-dried systems. Moreover, the results can be extended in the area of freeze-dried injectable products, considering the selection of studied excipients.

\section{Acknowledgement}

This work was supported by a grant of the Romanian Ministry of Education and Research, CNCS-UEFISCDI, project number PN-III-P1-1.1-PD-2019-0795, within PNCDI III.

\section{Conflict of interest}

The authors declare no conflict of interest.

\section{References}

1. Adeoye O, Alebiowu G, Evaluation of coprocessed disintegrants produced from tapioca starch and mannitol in orally disintegrating paracetamol tablet. Acta Pol Pharm., 2014; 71(5): 803-811.

2. Afrose A, White ET, Howes T, George G, Rashid A, Rintoul L, Islam N, Preparation of Ibuprofen Microparticles by Antisolvent Precipitation Crystallization Technique: Characterization, Formulation, and In Vitro Performance. J Pharm Sci., 2018; 107(12): 3060-3069.

3. Amelian A, Wasilewska K, Wesoły M, Ciosek-Skibińska P, Katarzyna W, Taste-masking assessment of orally disintegrating tablets and lyophilisates with cetirizine dihydrochloride microparticles. Saudi Pharm J., 2017; 25(8): 1144-1150.

4. Aslani A, Beigi M, Design, Formulation, and Physicochemical Evaluation of Montelukast Orally Disintegrating Tablet. Int J Prev Med., 2016; 7: 120: 1-8.

5. Baird JA, Taylor LS, Evaluation of amorphous solid dispersion properties using thermal analysis techniques. Adv Drug Deliv Rev., 2012; 64(5): 396-421.

6. Brookfield Texture Pro CT3 Application Software Operating Instructions Manual No. M08-373. Brookfield Engineering Laboratories, Inc. USA, 2009.

7. Casian T, Iurian S, Bogdan C, Rus L, Moldovan M, Tomuta I, QbD for pediatric oral lyophilisates development: risk assessment followed by screening and optimization. Drug Dev Ind Pharm., 2017; 43(12): 1932-1944.

8. Chu KR, Lee E, Jeong SH, Park ES, Effect of particle size on the dissolution behaviors of poorly watersoluble drugs. Arch Pharm Res., 2012; 35(7): 11871195.

9. Cilurzo F, Musazzi UM, Franzé S, Selmin F, Minghetti $\mathrm{P}$, Orodispersible dosage forms: biopharmaceutical improvements and regulatory requirements. Drug Discov Today, 2018; 23(2): 251-259.

10. Dixit M, Kini AG, Kulkarni PK, Shivakumar HG, A novel technique to enhancing the solubility and dissolution of flutamide using freeze drying. Turk $J$ Pharm Sci., 2012; 9(2): 139-150.

11. Dixit M, Kulkarni PK, Selvam P, Novel Technique to Enhancing the Solubility and Dissolution of Ketoprofen Using Freeze Drying. Int Res J Pharm., 2011; 2(12): 249-252. 
12. Dixit M, Kulkarni PK, Selvam P, Mohsin AS, Preparation and characterization of freeze dried crystals of ibuprofen. Int Res J Pharm., 2011; 2(12): 255-258.

13. European Pharmacopoeia, $9^{\text {th }}$ ed. EDQM, European Pharmacopoeia, Council of Europe, France, 2014.

14. Fina F, Madla CM, Goyanes A, Zhang J, Gaisford S, Basit AW, Fabricating 3D printed orally disintegrating printlets using selective laser sintering. Int J Pharm., 2018; 541(1-2): 101-107.

15. Garnero C, Aloisio C, Longhi M, Ibuprofen-Maltodextrin Interaction: Study of Enantiomeric Recognition and Complex Characterization. Pharmacol Pharm., 2013; 4(01): 18-30

16. Gulsun T, Cayli YA, Izat N, Cetin M, Oner L, Sahin $\mathrm{S}$, Development and evaluation of terbutaline sulfate orally disintegrating tablets by direct compression and freeze-drying methods. J Drug Deliv Sci Technol., 2018; 46: 251-258.

17. Iurian S, Bogdan C, Tomuță I, Szabó-Révész P, Chvatal A, Leucuța SE, Moldovan M, Ambrus R, Development of oral lyophilisates containing meloxicam nanocrystals using QbD approach. Eur J Pharm Sci., 2017; 104: 356-365.

18. Jones RJ, Rajabi-Siahboomi A, Levina M, Perrie Y, Mohammed AR, The influence of formulation and manufacturing process parameters on the characteristics of lyophilized orally disintegrating tablets. Pharmaceutics, 2011; 3(3): 440-457.

19. Nokhodchi A, Amire O, Jelvehgari M, Tehran P, Physico-mechanical and dissolution behaviours of ibuprofen crystals crystallized in the presence of various additives. Daru J Fac Pharm., 2010; 18(2): 74-83.

20. Porfire A, Tomuta I, Iurian S, Casian T, Pharmaceutical Quality by Design Principles and Applications, 2019; 193-207.
21. Rowe RC, Sheskey PJ, Quinn ME, Handbook of Pharmaceutical Excipients. $6^{\text {th }}$ Edition, Pharmaceutical Press, 2009.

22. Rus LM, Iurian S, Kacso I, Borodi G, Porav S, Hegheş SC, Iuga CA, Tomuţă I, Development of meloxicam oral lyophilisates: Role of thermal analysis and complementary techniques. Farmacia, 2019; 67(1): 56-67.

23. Scutellà B, Trelea IC, Bourlès E, Fonseca F, Passot $\mathrm{S}$, Determination of the dried product resistance variability and its influence on the product temperature in pharmaceutical freeze-drying. Eur J Pharm Biopharm., 2018; 128: 379-388

24. Shah B, Kakumanu VK, Bansal AK, Analytical Techniques for Quantification of Amorphous/ Crystalline Phases in Pharmaceutical Solids. J Pharm Sci., 2006; 95(8): 1641-1665.

25. Siow CRS, Heng PWS, Chan LW, Application of freeze-drying in the development of oral drug delivery systems. Exp Opin Drug Deliv., 2016; 13(11): 15951608.

26. Slavkova M, Breitkreutz J, Orodispersible drug formulations for children and elderly. Eur J Pharm Sci., 2015; 75: 2-9.

27. Suciu S, Iurian S, Bogdan C, Iovanov R, Rus L, Moldovan M, Tomuta I, QbD approach in the development of oral lyophilisates with ibuprofen for paediatric use. Farmacia, 2018; 66(3): 514-523.

28. Türkmen Ö, Şenyiğit ZA, Baloğlu E, Formulation and evaluation of fexofenadine hydrochloride orally disintegrating tablets for pediatric use. J Drug Deliv Sci Technol., 2018; 43: 201-210. 